\title{
Investigation of deviations in SI-engine behaviour due to manufacturing tolerances in cylinder heads
}

\author{
Stephan Zeilinga ${ }^{1} \cdot$ Hermann Rottengruber $^{1} \cdot$ Aristidis Dafis $^{1}{ }^{1} \cdot$ Alexander Wagner $^{2} \cdot$ Torsten Stolt $^{3}$. \\ Franz Josef Feikus ${ }^{4}$
}

Received: 3 March 2021 / Accepted: 22 June 2021 / Published online: 22 July 2021

(c) The Author(s) 2021

\begin{abstract}
Cast engine components are experiencing ever tighter tolerance requirements and at the same time a more complex cast design. The geometries, some of which are inaccessible, are tested for quality assurance on the basis of relevant component characteristics, among other things. The position check measures the actual position of a feature in a spatial dimension. Information about the alignment and geometry of the combustion chamber cannot be derived from the measurement methods applied. The use of three-dimensional measuring methods, e.g., imaging by computer tomography, can additionally record the spatial component position and the component geometry. Further measurement data can be derived from this, which serves to increase process reliability and component quality, and to increase component quality within an entire component batch. On the one hand, the cylinder head limits the working space by the roof of the combustion chamber, on the other hand, the cylinder head has a significant influence on the charge movement, especially at the beginning of the intake flow, due to the geometry of the intake ducts. On account the high demands of modern gasoline engines with tumble combustion process paired with Miller operation at partial load, variable timing, etc., mixture formation is important for efficient operation. Mixture formation in air- and wall-guided combustion processes depends on the components air duct and injection. From the point of view of cylinder head production, the mixture formation component air guiding is an elementary development approach for implementing efficient and sustainable component production while ensuring component properties. From this, the question can be derived as to what influence, for example, different dimensional tolerances in the combustion chamber size have on engine operation. To address this question, 3D simulations and physical test bench measurements were performed. With a variation of the above-mentioned intake duct and combustion chamber geometries and due to manufacturing tolerances, simulation results and measurement data were evaluated, analysed and presented in this paper. The influence of manufacturing-relevant tolerance deviations in the early process step of cylinder head production on combustion engine operation can be recognised in different ways.
\end{abstract}

Keywords Cylinder head · Cfd-simulation · CT-scanning · Compression ratio

Aristidis Dafis

aristidis.dafis@ovgu.de

1 Otto Von Guericke University Magdeburg, Universitätsplatz 2, 39116 Magdeburg, Germany

2 Nemak Wernigerode GmbH, Giesserweg 10, 38855 Wernigerode, Germany

3 Microvista GmbH, Am Mönchenfelde 12, 38889 Blankenburg, Germany

4 Nemak Europe GmbH, The Squaire 17, 60549 Frankfurt/M, Germany

\section{Motivation}

The technological advancement of production processes makes it possible to produce components in ever larger quantities at low cost. However, this leads to higher requirements that are placed on the components. In the case of cylinder head production, a very elaborately designed component geometry is added, which must be implemented in a complex production chain and is already significantly influenced in the foundry. With additional tolerance requirements, such complex geometries increase the risk of growing component scrap, which raises production costs and increases the $\mathrm{CO}_{2}$ 


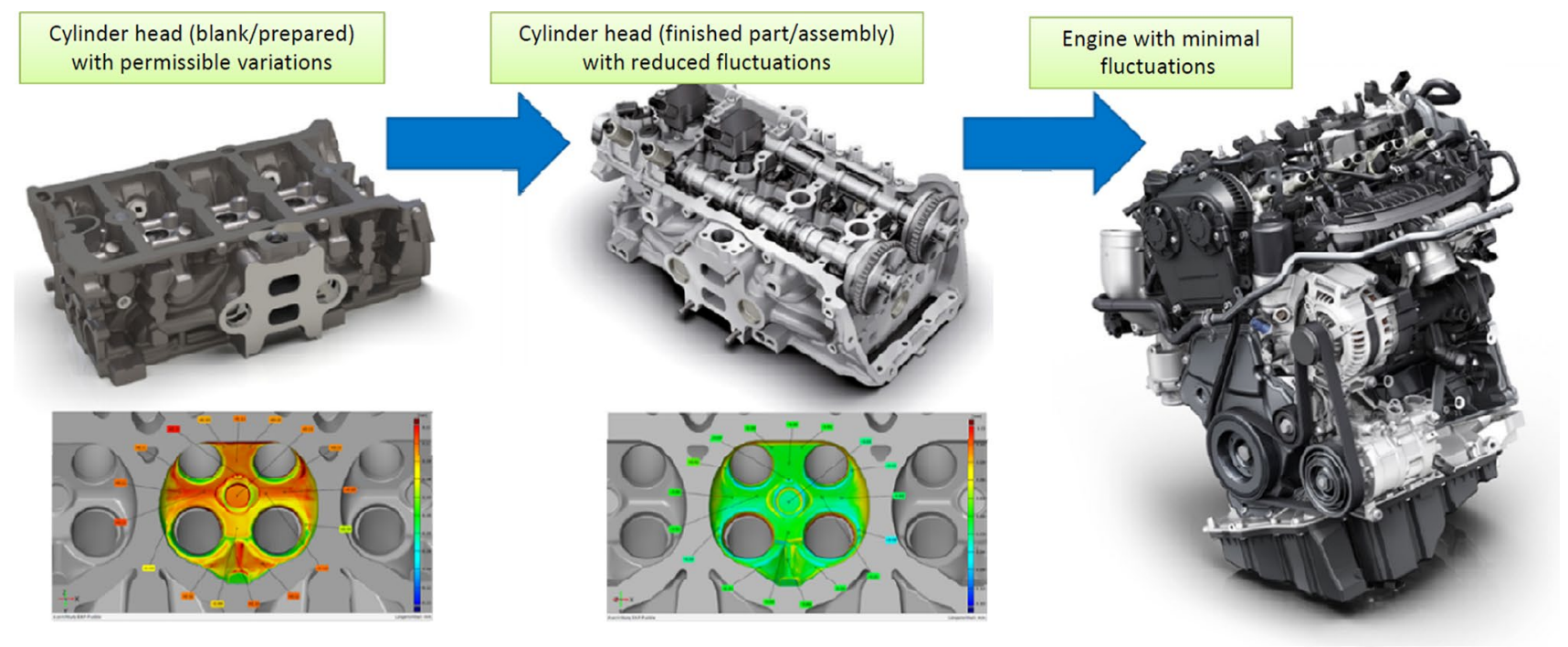

Fig. 1 Development of tolerance variations in the gasoline engine with tolerance-optimised component pairing

emissions of the individual component. The step-by-step production chain of a cylinder head can be seen in Fig. 1.

A possible way to holistically reduce the $\mathrm{CO}_{2}$ burden of production is to create "digital twins" or dimensionally matched pairs of components. If an ideally fitting component partner existed for each component of an assembly, parts with significantly higher manufacturing tolerances could be used, provided that the dimensional deviation is comprehensively documented and a suitable counterpart exists.

This means; however, that much higher requirements are placed on the test procedures. One-dimensional inspection methods, such as a simple position determination of a defined feature, are not suitable for the required threedimensional resolution of the respective component geometry. Digital high-resolution measuring methods must be integrated into series production, which allow three-dimensional component measurement in a production-cycle cycle time. One way of digitising the cylinder head geometry is the computer tomography (CT). CT technology is already being used for spot checks for defect analysis or for the examination of wall thicknesses or the identification of sand residues and chips. Modern in-line CT's also offer the possibility to $\mathrm{X}$-ray several components in a very short time with sufficient accuracy. This means that larger lots can also be evaluated. A complete integration of the test into a serial production process is possible. The corresponding knowledge for the targeted component evaluation with regard to the mentioned criteria also of larger lots already exists. In addition, it is necessary to achieve a measuring accuracy that enables engine-relevant deviations in the component geometry to be detected by means of CT scans. However, it is first necessary to know the influence of dimensional deviations on motor operation.
An essential feature influencing the combustion process is the combustion chamber. In addition to its geometry (size and shape), the location is also of interest. The combustion chamber roof is formed by the cylinder head. While diesel engines often use simple, flat surfaces, gasoline engines have structured, dome-shaped designs. Their shape and position are formed during the casting process and remain unchanged for the majority of engines until the cylinder head is in its final machined state. The forming process thus has a direct influence on the operating behaviour of the engine. The combustion chamber insert in the casting mould determines the combustion chamber shape, but also the position of the combustion chamber roof. Today's inspection methods (3D measuring machines) only consider the deviation in height and position. Other features such as the three-dimensional shape or the combustion chamber volume are determined with these methods. To reliably achieve the ambitious emission targets and to achieve minimum $\mathrm{CO}_{2}$ emissions, it is therefore necessary to answer the question of how the production-related deviations of the combustion chambers can be checked and what influence they have on the emission behaviour [2].

Thus, the real deviations as result of manufacturing tolerances form the boundary conditions of this investigation. Consequently, these must first be identified as this is the first step in the investigation. Computer tomography is used to scan the component, in this case the cylinder head, and detailed images can be derived. Starting from an "ideal" component, the geometric boundary conditions can be defined and characteristics for the further examination can be worked out. This procedure is explained below. Subsequently, CFD simulations of the intake and compression stroke are carried out to generate spatially resolved results 
of the mixture formation and flow-relevant variables. Finally, initial findings from the simulation results are validated with measurement results from test bench operation.

\section{Computer tomography as a measuring method for series production}

Computer tomography is an imaging measurement method that was first brought to maturity in the field of medical technology. Shadow images are generated by means of $\mathrm{X}$-rays, e.g., Fig. 2. The rays passing through the measuring object are absorbed as a function of density, so that the transmitted X-ray intensity is measured at the detector. For a two-dimensional representation of a section, several images must be acquired in different positions around a fixed axis of rotation. To describe the function of a body uniquely, the line integrals of an angle $0^{\circ} \leq \Phi \leq 180^{\circ}$ are measured and combined. The function of a section and the derivation of a sectional plane in a two-dimensional image can thus be derived as a function via the measurement object. By a rotational movement around the measuring object, the $\mathrm{X}$-ray intensity in the necessary angular interval $\Phi$ can be used for the two-dimensional description of the sectional plane. If the measuring object is also moved in translation, a so-called spiral or helix CT is produced [3, 4].

For industrial applications, series-oriented measurement tasks must be implemented in CT. A fast CT, also known as inline CT or ATline-CT, is characterized by a high scanning speed. Due to the overlapping helix movement of detector and tube around the component, a cylinder head can be digitized in 15-20 s, for example, depending on the set feed rate and component size. In industry, the use of inline computer tomography enables interference-free three-dimensional testing of materials and components. The high scanning speeds enable the digitization of the internal component

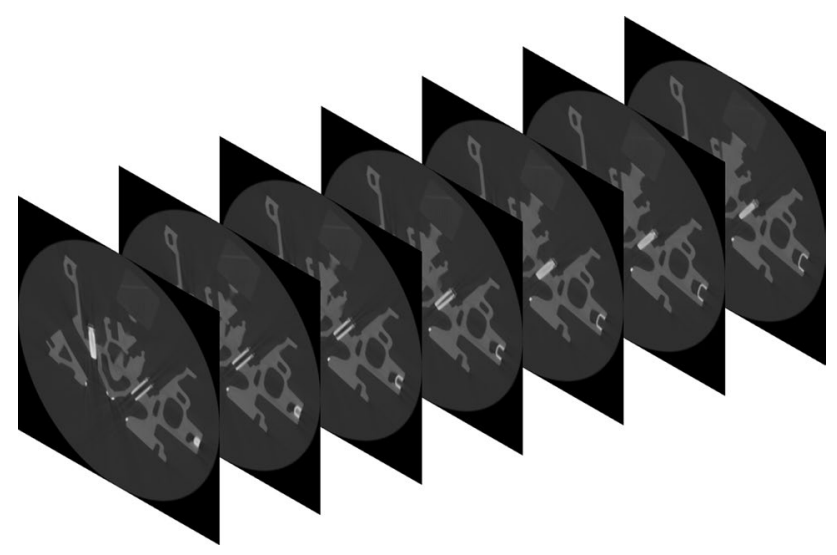

Fig. 2 Cutting planes from a cylinder head CT scan structure, whereby various factors and measurement tasks must be taken into account $[4,5]$.

In order to fulfil a measuring task, it is necessary to prove the measuring equipment capability, e.g. according to VDE 2630. By means of repeat scans and a tactile reference, the measuring equipment capability can be proven with sufficient accuracy, as for example in [6] described.

The advantage of the fast availability of the scan data is counteracted by two disadvantageous features of a fast CT. On the one hand, in the case of high material thicknesses or long component edges, the introduced energy input is not sufficient to obtain artefact-free surfaces. Secondly, the relatively large detector apparatus limits the achievable resolution. Unlike tactile methods, an analysis of the measuring equipment capability must be considered separately for each individual measuring point. Both the artefact formation and the component geometry in the area of the measuring point have a great influence here, so that optimum component positioning must be considered equally.

An important influencing factor for the realisation of the measuring task is the alignment of the scan data to the CAD used. This alignment should be seen as the basis for automatic analysis. In this case the alignment is carried out after the initial images of the component. If there are problems with the surface finding here due to the casting process or due to incorrect component alignment, these affect all measured values. In order to obtain stable values, the ISO50 algorithm developed for imaging measurement procedures is used. This algorithm defines the component edge exactly at $50 \%$ of the grey value drop from the material-grey value to the background grey value. As a side effect, a resolutiondependent averaging of the surface points takes place here. This side effect is useful for averaging unevenness caused by sand adhesion or slight core breakouts in such a way that a measured value does not exceed the tolerance limit.

Since at each individual measuring point the accuracy of the surface detection in relation to the radiolucency of the component combined with the surface course must be considered, it is necessary to develop an individual measuring strategy for each individual measuring point. To fulfil this measurement task, the subvoxel accuracy of the scan data must also be exploited. In areas of strong artefact formation, surface detection is also only possible to a limited extent. Here it is necessary to adapt the measuring plan to the process-related conditions and thus, if demanded, to find an equivalent measuring point. [7]

As a result of the repeat measurements, the mean value and standard deviation are determined. The calculated statistics compare the variation (offset) of the process to specified limits. Cg and Cgk are capability indices which are logically restricted, so the variation within the tolerance will not be considered the variation of the measuring instrument. Furthermore, in comparison to a tactile 
measurement, the systematic error of the computer-tomography must be determined for each measurement point. Usually the results of a tactile measurement according to the measurement plan are used as a reference. In practice, however, it has been shown that tactile measurement values require thorough validation so that systematic errors can be excluded or neglected. The systematic error of the computer tomography calculated by comparison with the tactile measured values is used as an offset of a measured value in a next step. As a result, comparability to tactile measurement is given. The following figure shows an example of the standard deviation for a measured value (Fig. 3).

After optimising the measuring process, the measured values of the inner contours must be checked once again. For this purpose, selected components should be cut up at the respective measuring points and then remeasured tactilely. The deviation determined in the process shall be placed in relation to the scan results. Two conclusions can be drawn from this comparison:

1. All measured values must agree within the scope of the fluctuations and the tactile readings leading to failure should also indicate failure in the CT scan.

2. The fluctuation of the deviation of the CT measurement values from the tactile measurement values must be a minimum.

Considering the measuring equipment capability and the target variables to be recorded by an inline CT, it is basically possible to digitise a component in series production. The challenge here is the trade-off between measuring time and cycle time. One way to reduce the measurement time is to limit the variables to be evaluated. Within a cylinder head there are various approaches to check the component quality. With regard to the acquisition of component geometry, the scan resolution can be increased in specific component areas. This is useful, for example, for the combustion chamber volume so that the real combustion chamber volume can be derived. With the combustion chamber volume of the raw part, the expected compression volume can then be determined in advance, considering the influences of further processing and potential component pairings. If a compression volume is created whose condition is outside the required limits, an optimum compression ratio can be derived and implemented by adapting other assembly elements [8].

\section{Production of test components with feature isolated deviations}

For the identification of automatable features of the combustion chamber, the knowledge of the process of the raw part production is decisive. The contour of the cylinder head is formed by permanent mould parts in gravity die casting. The influences on the final blank geometry are manifold. Basically, an attempt is made to reproduce the "ideal" (= design data) as accurately as possible. When designing the combustion chamber insert, it must be noted that the casting shrinks during solidification and cooling, while the mould expands under the influence of temperature. In addition, all mould parts must be coated to protect them against the melt. The coating has a variable thickness depending on the technology and can wear out locally. Decisive for the dimensional accuracy of the castings are the production parameters, such as the temperature of the mould, the temperature of the melt or also the condition of the coating during casting and the actual behaviour of the melt during its solidification and cooling in a complex mould, possibly with shrinkage hindrance.

Starting from the cylinder head blank production, the combustion chamber geometry can vary with regard to two essential system parameters. Separate metallic inserts in the mould are used for the combustion chamber roof (Fig. 4). The internal cavities (water and oil channels) are represented by lost cores, which must be manufactured separately and placed in the mould before each casting. This creates a further potential for the occurrence of dimensional deviations from the specified shape and position of the combustion chambers.

The position of the cores in the cylinder head is tolerated with a permissible deviation in terms of their height and longitudinal deviations. Furthermore, the mould parts,
Fig. 3 Standard deviation to a measured value for 25 repeated measurements

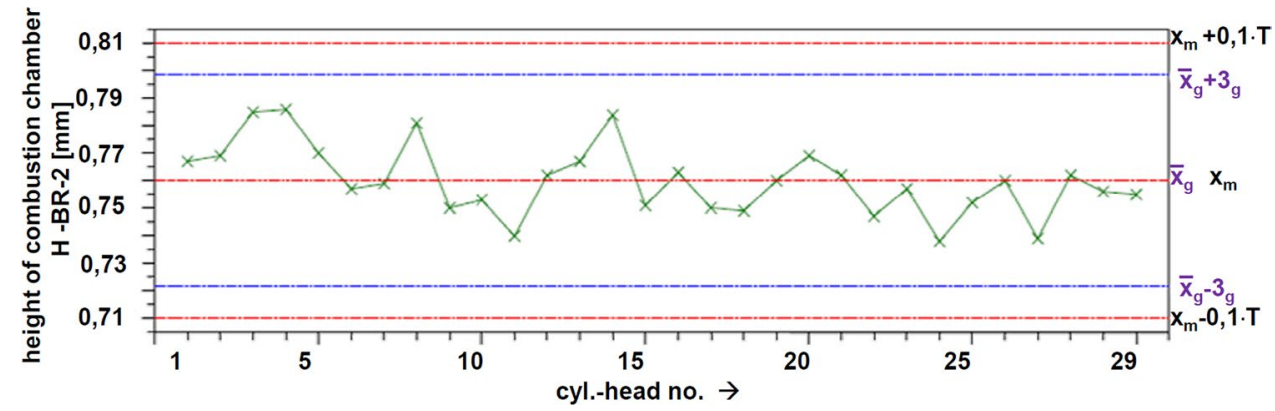




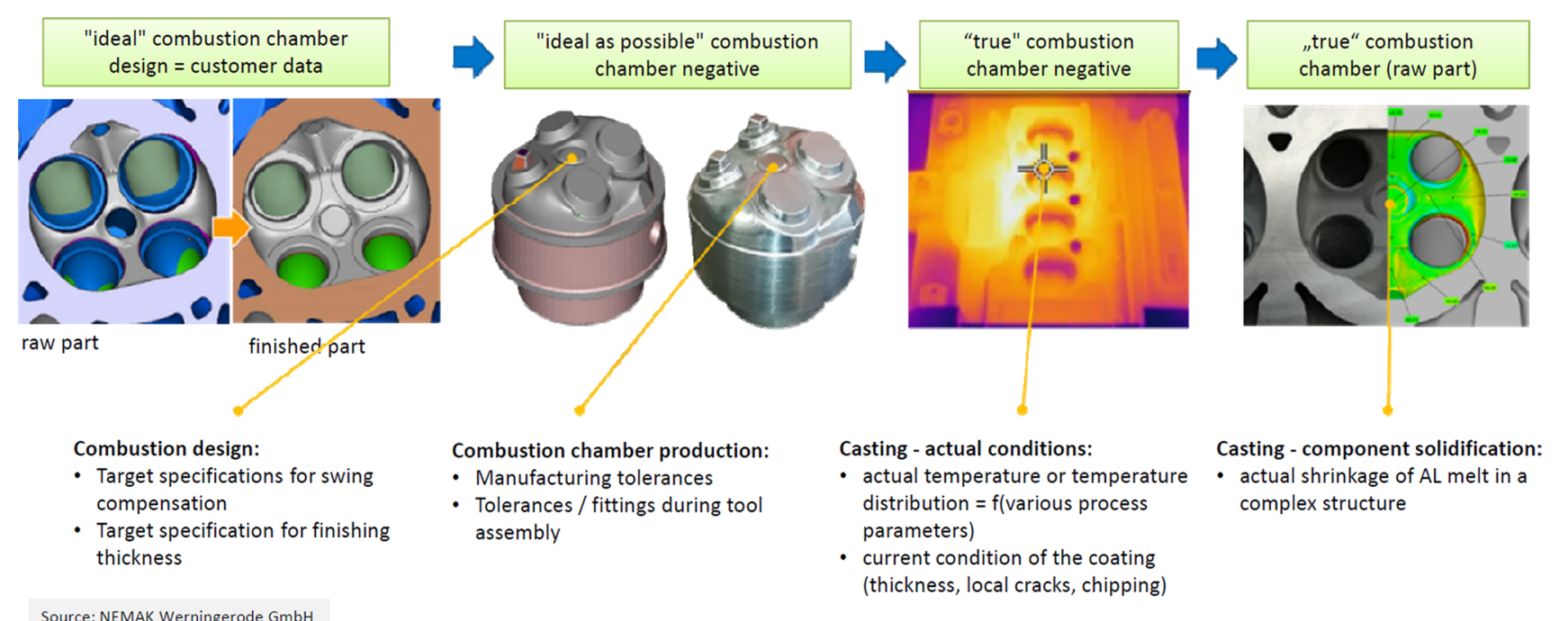

Fig. 4 Major influences on the "true" combustion chamber design [1]

but also the moulds for the production of the cores are subject to wear. Over the lifespan of the moulds, this wear causes a steady erosion of the material, which can cause a material offset at the cast combustion chamber and thus lead to a reduction of the combustion chamber.

Due to the functionality of the assembly, the shape and position of the combustion chamber contour in the cylinder head is subject to very tight tolerances and is strongly determined by the individual combustion chamber mould inserts (design, manufacture, wear), their positioning in the mould base plate and the temperature fluctuations in the casting process. The stochastic deviations of the real combustion chamber geometry (shape and position) resulting from the influences mentioned above can be grouped as follows:

(a) Deviations in the cylinder axis (combustion chamber height shifts), e.g., due to temperature influences (mould growth, mould distortion),

(b) Deviations in the component longitudinal/transverse axis, also due to temperature influences (mould growth, mould distortion) (c) Deviations in shape/extent due to mould wear and coating application and wear

(d) Combinations of a, b and c

The actual shape and position of the core is also subject to additional influences from the design and manufacturing of the cores (e.g., mould wear, mould offset), as well as assembly and alignment in the pre-heated moulds. Smooth assembly between core and die-supports requires clearance, which can affect the accuracy of the core layers.

The combustion chamber deviations can be converted into component characteristics. In the further course of this work, the characteristics shown in will be defined as CAS feature for cylinder axis shift and as CCV feature for combustion chamber volume (Fig. 5).

\subsection{Manufacturing of the test parts}

Series production of the reference cylinder head (4-cylinder gasoline DI-engine) is carried out on automatic multi-station lines with automatic core feeding. However, the statistical evaluation of long-term measurements on serial components shows only a very low probability of the occurrence
Fig. 5 Overview of the variation of the combustion chamber deviation

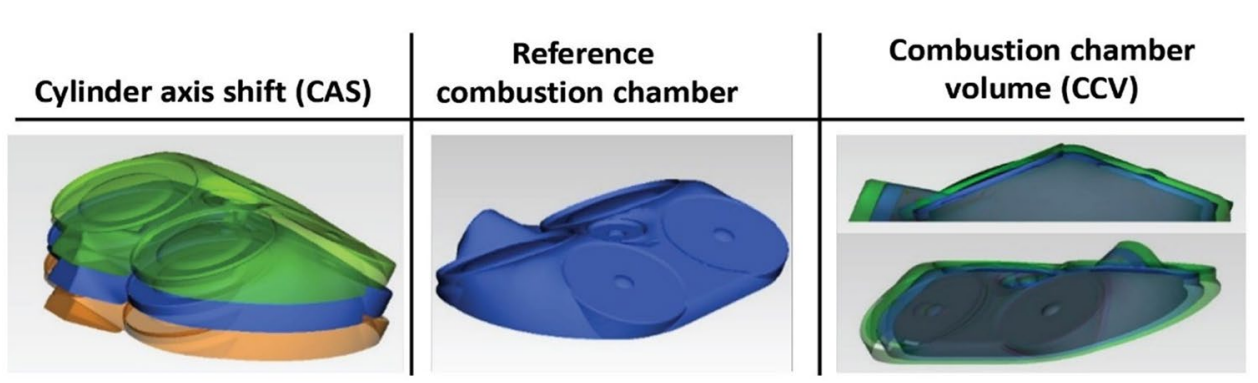


of the previously defined combinations of characteristics on a single component. The removal of test parts from the current series was therefore not an option for the development project.

For maximum precision in the implementation of the defined feature combinations and for a reduction of the adjustment and testing effort in the foundry, a final mechanical complete combustion chamber machining was carried out. In total, 19 cylinder heads were provided for this investigation and are enlisted in Table 1. In comparison to the series cylinder heads, all test parts were manufactured with a defined material offset in the combustion chamber area (machining allowance) to enable subsequent mechanical machining.

All parts of the production lot were first measured tactilely (using a 3D coordinate measuring machine). The aim was to identify parts with the best possible port core positions. In addition, a CT scan of the test parts was performed to identify and exclude test parts with relevant internal defects.
The most suitable parts from the trial lot were then mechanically processed to the desired shape (offset) and position (height offset). This ensured that the reference components almost perfectly matched the combustion chamber deviations defined in the test plan. Fig. 6 shows a combustion chamber before and after machining.

To verify that the final test bench samples were in accordance with the test plan, the machined components in the combustion chamber and intake duct area were optically measured using optical 3D metrology by GOM. These measurements also served as a reference for the inline CT measurements at the project partner Microvista. Fig. 7 shows some examples of GOM results.

To achieve the required measurement accuracies in the CT X-ray process as well, it had to be calibrated. This calibration is based on the optical 3D metrology by GOM, which measured values at defined points. The basis for the definition of the required measuring point matrix is formed by the series-relevant standard measuring points, whereby here only those points were used as a reference which allow statements to be made about the combustion chamber geometry

Table 1 Investigated components and their characteristics

\begin{tabular}{|c|c|c|}
\hline \multicolumn{3}{|c|}{ Characteristic: combustion chamber (CC) volume } \\
\hline \multirow[t]{2}{*}{ Component \# } & \multicolumn{2}{|l|}{ Feature } \\
\hline & $\overline{\mathrm{CCV}}$ & CAS \\
\hline Nr. 1 & Ideal & Ideal \\
\hline Nr. 2 & Ideal & All CC too high within tolerance \\
\hline Nr. 3 & Ideal & All CC too low within tolerance \\
\hline Nr. 4 & Ideal & $\mathrm{CC}$ ideal $+\mathrm{CC}$ too high within the tolerance \\
\hline Nr. 5 & Ideal & $\mathrm{CC}$ ideal $+\mathrm{CC}$ too low within the tolerance \\
\hline Nr. 6 & Ideal & $\begin{array}{l}\mathrm{CC} \text { too high within the tolerance }+\mathrm{CC} \text { too low } \\
\text { within the tolerance }\end{array}$ \\
\hline Nr. 7 & Ideal & All CC too high out of the tolerance \\
\hline Nr. 8 & Ideal & All CC too low outside of the tolerance \\
\hline Nr. 9 & Ideal & $\mathrm{CC}$ ideal $+\mathrm{CC}$ too high outside of the tolerance \\
\hline Nr. 10 & Ideal & $\mathrm{CC}$ ideal $+\mathrm{CC}$ too low outside of the tolerance \\
\hline Nr. 11 & Ideal & $\begin{array}{l}\mathrm{CC} \text { too high outside of the tolerance }+\mathrm{CC} \text { too } \\
\text { low outside of the tolerance }\end{array}$ \\
\hline Nr. 12 & All CC scaled down & All CC in nominal dimension \\
\hline Nr. 13 & All CC scaled up & All CC in nominal dimension \\
\hline Nr. 14 & $\mathrm{CC}$ ideal $+\mathrm{CC}$ scaled down & All CC in nominal dimension \\
\hline Nr. 15 & CC ideal + CC scaled up & All CC in nominal dimension \\
\hline Nr. 16 & CC scaled down + CC scaled up & All CC in nominal dimension \\
\hline \multicolumn{3}{|c|}{ Characteristic: Inlet duct position } \\
\hline & $\mathrm{CCV}$ & Inlet duct position/form \\
\hline Nr. 17 & Ideal & Inlet duct old core box \\
\hline Nr. 18 & Ideal & $\begin{array}{l}\text { Inlet duct enlarged (core box does not close } \\
\text { completely) }\end{array}$ \\
\hline Nr. 19 & Ideal & Inlet duct position too low \\
\hline
\end{tabular}


Fig. 6 Comparison of cast (left) and machined (right) combustion chamber contour
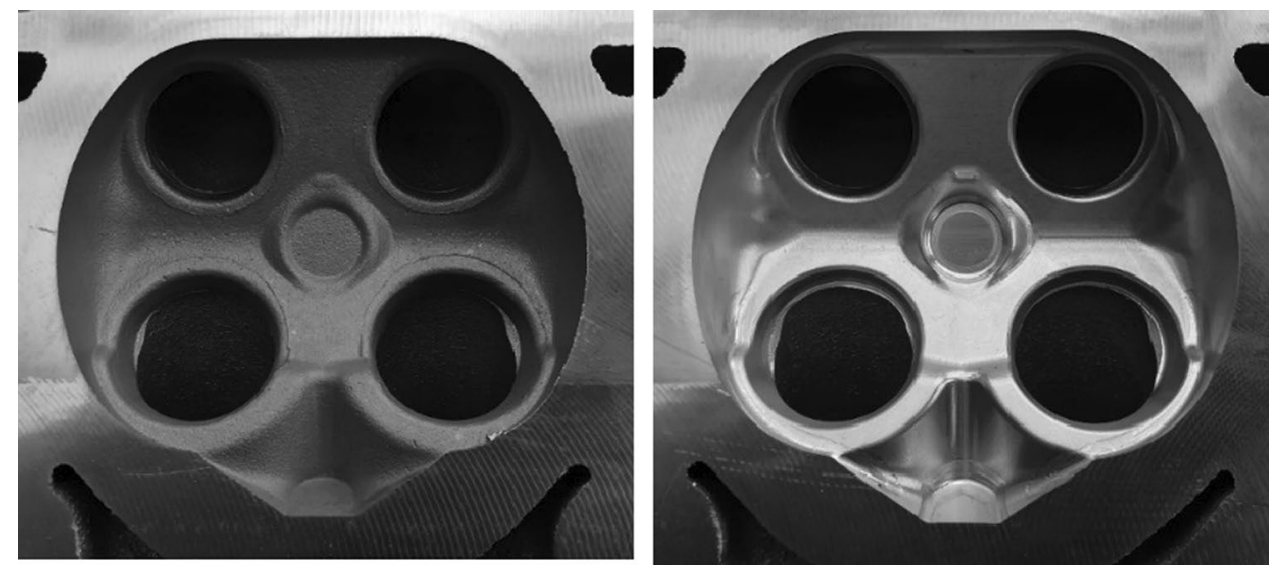

\section{Combustion chamber deviation of different test samples}

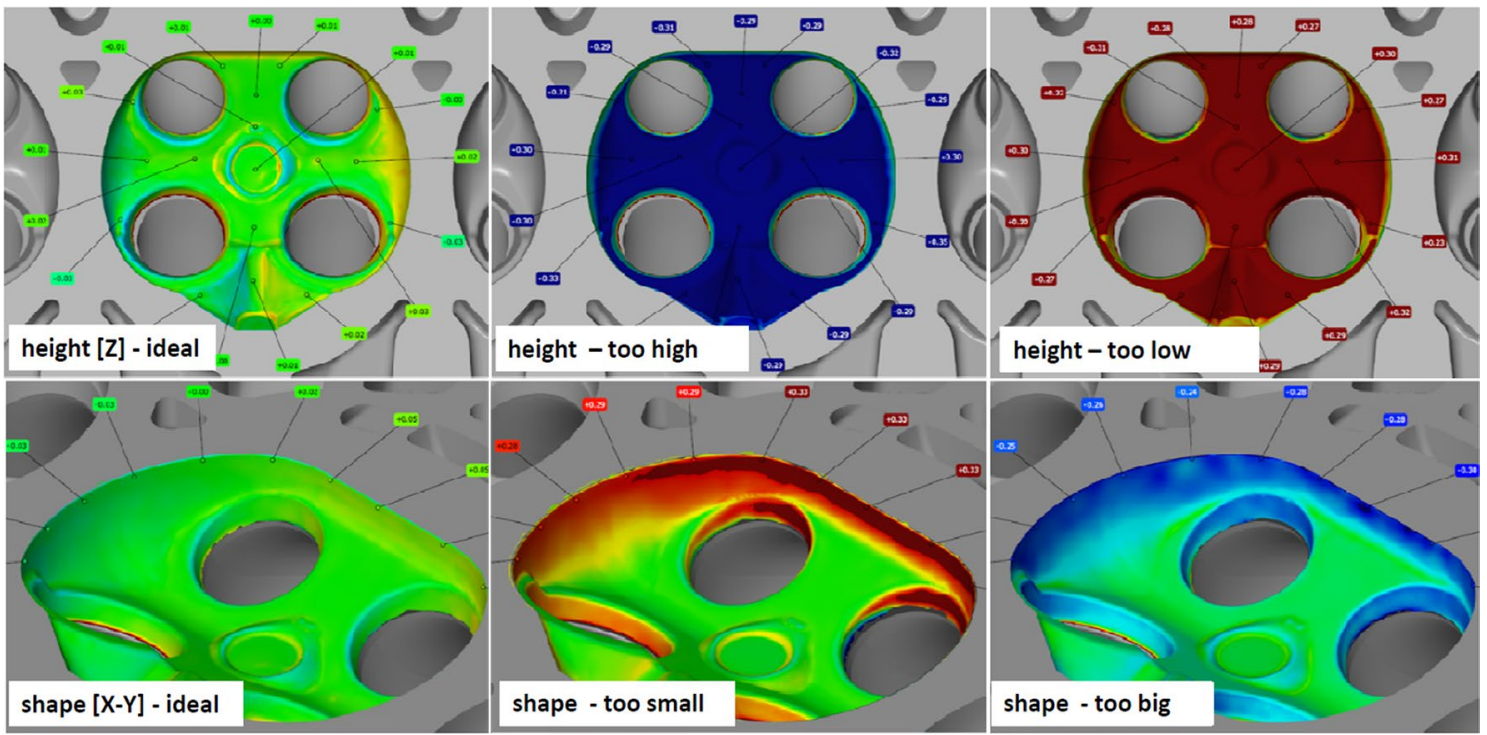

Fig. 7 Examples of GOM measurements on different test bench samples (top: combustion chamber height [Z], bottom: combustion chamber shape $[\mathrm{X}-\mathrm{Y}]$, from left to right: ideal, too high/small, too deep/big)

or position. To improve the informative value of the measurements with regard to the determination of the combustion chamber volume, the measuring point matrix was extended by additional measuring points.

\section{Simulation of mixture formation}

To identify possible influences of the defined characteristics, the mixture formation was simulated. The simulation tool used is AVL Fire ${ }^{\mathrm{TM}}$ version 2017.1, which uses the combustion chamber and the intake and exhaust ducts of the research engine as the basis for modelling.

Combustion chamber characteristics were derived from the production of blanks, the characteristics of which were converted into positive and negative tolerance orientation. A feature-isolated production is nevertheless not feasible, and the measurability cannot be clearly estimated in advance. Therefore, the inlet flow was simulated transiently with changed combustion chamber surfaces according to the characteristics, so that a differentiation of the developed combustion chamber characteristics is possible. The tolerance limit is $\pm 150 \mu \mathrm{m}$ for the position of the combustion chamber roof. For the displacement of the combustion chamber roof in the cylinder axis, a maximum deviation from the nominal dimension of $\pm 300 \mu \mathrm{m}$ was modelled. In addition, a combustion chamber volume scaling of 5\% was carried out to reproduce the mould wear. 

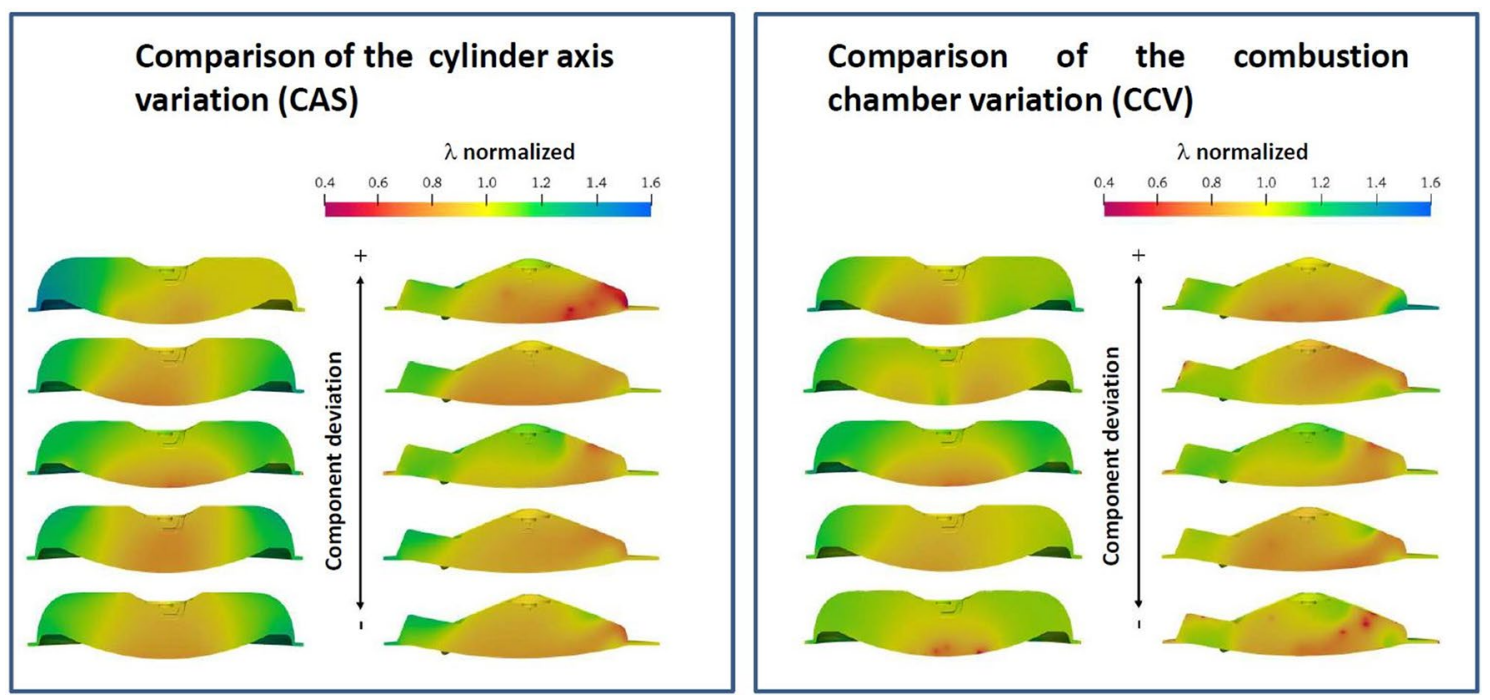

Fig. 8 Local air-fuel ratio at the end of compression (TDC)

\subsection{Mixture formation at the end of compaction}

The mixture formation state at the end of the compression cycle is shown in Fig. 8. The characteristic values are arranged from bottom (combustion chamber reduction) to top (combustion chamber enlargement). The reference model (no manipulation of characteristics) is positioned in the middle position. The fuel distribution is shown using the $\lambda$ distribution in the central sectional views XZ plane (right) and YZ plane (left).

The comparison of the models with a displacement of the combustion chamber roof along the cylinder axis (feature CAS) shows locally higher fuel concentrations in the case of a combustion chamber reduction, whereby the gradient of the fuel distribution towards the edge areas is less pronounced (see YZ plane). With increasing combustion chamber volume, the gradient of fuel distribution to the peripheral areas increases slightly, at least visually. If the combustion chambers are too large, an uneven fuel distribution can be seen, especially in the YZ plane.

The comparison of the models with a manipulation of the combustion chamber shape (feature CCV) shows a less pronounced gradient of the fuel distribution towards the edge areas in the case of a combustion chamber reduction. As the combustion chamber volume increases, the gradient of fuel distribution to the peripheral areas increases slightly visually. A larger combustion chamber compared to the reference model shows an increasing unevenness of fuel distribution, especially in the YZ plane.
The visual contrast allows a direct comparison of the cutting planes to each other. The fuel distribution cannot be determined globally. In order to evaluate the equal fuel distribution in the entire combustion chamber, an equal distribution index for the model state of the TDC was used:

$U I=1-\left(\frac{\int \frac{\sqrt{\left(\lambda_{i}-\bar{\lambda}\right)}}{\bar{\lambda}} d V}{V_{G e s}}\right)$,

where $\lambda_{i}$ describes the combustion air ratio of a volume element, $\bar{\lambda}$ the mean value of the combustion air ratio or the global combustion air ratio, and $V_{\text {Ges }}$ the total volume of the considered model. UI indicates that there is a homogeneously mixed fuel distribution ( $\mathrm{UI}=1$ ) or no mixing can be found in the model ( $U I=0)$.

If a one-dimensional key figure is used to describe the fuel distribution, the result for the simulations discussed is the picture shown in Fig. 7. The Uniformity Index of the manipulated models is plotted against the corresponding compression ratio. At a compression ratio of 11.58 (centrally located), the model is positioned with the reference combustion chamber. The deviations in feature CAS span a wide volume difference between the models with the smallest and largest compression ratios. The difference in equal distribution is therefore smaller than that of feature $\mathrm{CCV}$. The tendency is that with increasing compression 
ratio a slight improvement in fuel uniformity can be seen. Similarly, it can be seen that the fuel equalisation no longer drops sharply when the combustion chamber volume is too large. With smaller combustion chambers, however, the uniform distribution increases.

Due to the few support points for polynomial formation to describe the feature-specific uniform distribution properties, this consideration is a purely analytical procedure to specify and estimate the differences. A marginal featurespecific dependency is therefore discernible.

Clear dependencies of the defined combustion chamber characteristics are recognisable here, but only in the case of very large deviations from the nominal dimension, which is why these characteristics are unlikely to be present in series applications. Therefore, primarily a dependence of the compression ratio or the combustion chamber volume can be derived.

\section{Examination of component deviations on the engine test bench}

The test vehicle belongs to the Volkswagen Group's EA888 Gen.3 B series. The engine is a turbo-charged gasoline engine with a dual injection system. Characteristic for the partial load (TL) is the use of Miller valve-timing. The full load behaviour is shown with a conventional valve lift [9]

For the investigation of the operating behaviour due to form deviations of the combustion chamber, a first comparison of the stationary operating behaviour and investigations of the resulting knocking behaviour of the boundary samples shall be presented here. The comparison of stationary engine operation is to show the influence to what extent the combustion chamber manipulations or the defined combustion chamber characteristics influence the operating field of the engine. From the operating parameters it can be derived which parameters for the corresponding load requirement are additionally manipulated compared to the comparison measurement. Thus, a dependence of the mixture formation can be differentiated from the dependence of the compression ratio. The comparison of the ignition limits should show which primary quantity has a significant influence on engine operation.

\subsection{Comparison of the map measurements}

The following Fig. 9 shows the differential maps of the components with greatly reduced compression ratio. The components differ in terms of their combustion chamber shape. Component \#07 has feature CAS and component \#13 has feature CCV (Table 1 for component features). The minimum compression ratios of the test parts are $\varepsilon_{\min }=11.45$ at $\# 07$ and $\varepsilon_{\min }=11.42$ at \#13. The analysis full load operation

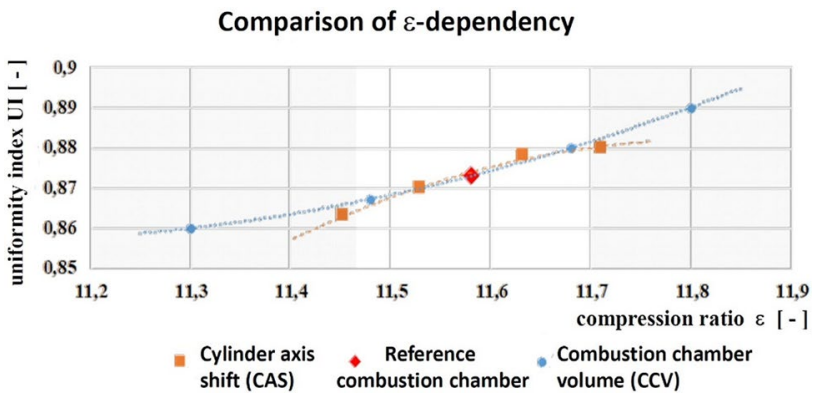

Fig. 9 Calculated equal distribution index of the feature-manipulated individual models in relation to the associated compression ratio

at \#07 shows that the HET (high-end torque) range is operated with additional fuel enrichment and a concomitant increase in specific fuel consumption. If component \#13 is also considered, an identical behaviour can be seen. Although a slightly lean operating condition can be seen, the load is equally limited due to the lack of compression. The boost pressure is increased by raising the exhaust gas enthalpy, which results in later ignition timing and poorer specific fuel consumption.

In the LET (low-end torque) range, slightly lean operating conditions can be observed. These are also due to the geometrical properties. The ignition timing are more efficient due to the lack of knock detection. Both components show the same properties in this area.

In the range above the Miller full load (1750 rpm to $2500 \mathrm{rpm}$ and 15 bar BMEP) a slight fuel increase is visible at \#07. Taking the control parameters into account, an increase in boost pressure can be seen here, with otherwise the same parameterization. The comparison with component \#13 shows the same tendencies, with a slightly higher level of development. Due to the higher boost pressure, more fuel is injected and the mixture formation is worse. This can be seen, for example, in the sharp rise in $\mathrm{CO}$ emissions.

The comparison of the differential maps shows primarily the same operating characteristics of the two cylinder heads. A differentiation of the characteristics regarding the combustion chamber enlargement is therefore not derivable. In addition, it is stated that the combustion chamber volume varies between "component within the specifications" (OK) and "component not within the specifications" (NOK).

Components \#08 (feature CAS) and \#12 (feature CCV) have a greatly increased compression ratio. The difference maps are shown in Fig. 10. The maximum compression ratio of component \#08 is $\varepsilon_{\max }=11.7$ and of component \#12 for $\varepsilon_{\max }=11.69$.

The comparison shows an additional full load increasing in the area of the HET. In comparison to the comparative measurement, no further differences can be seen with regard to the operating mode. If the fuel consumption is considered, 

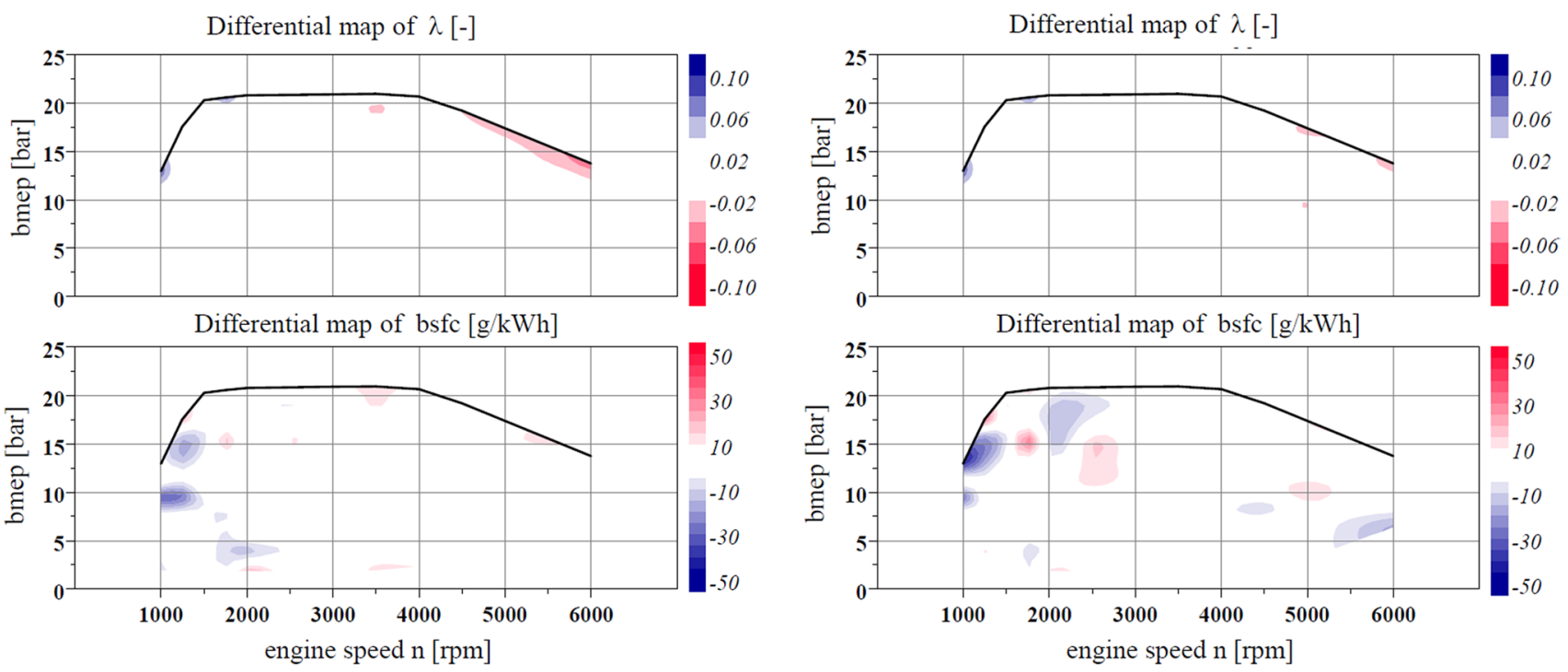

Fig. 10 Difference map of part \#07-CAS feature with increased NOK volume (left); Difference map of part \#13-CCV feature with increased NOK volume (right)

a lower fuel consumption is recorded in the HET, despite the slight increase in the fuel quantity. In addition, various hot spots are emerging, which show lower fuel consumption compared to the reference. For example, the operating point 4000 rpm and 9 bar BMEP for component \#08 shows a marginal reduction in specific fuel consumption. This property can also be seen on component \#12 in expanded form. The direct comparison of the measuring points shows that the burning time is shortened. The combustion centre of gravity is adjusted to $8^{\circ} \mathrm{CA}$ a. TDC. The detected ignition delay is identical. The test parts with lower $\varepsilon$ show here a faster fuel conversion, which leads to a slight increase in efficiency. This points to improved fuel homogenisation. The situation is similar in the Miller full load range. Regardless of the feature, a slight fuel saving is visible at $2500 \mathrm{rpm}$ and $12 \mathrm{bar}$ $\mathrm{p}_{\mathrm{me}}$. The operating parameters are almost identical and the combustion time is much shorter than that of the comparable engine, resulting in an increase in efficiency. Outside the Miller range, on the other hand, a consumption disadvantage can be observed. Due to the full valve lift and the longer valve opening time, the cylinder charge increases. Due to the increased compression ratio, the ignition timings are shifted
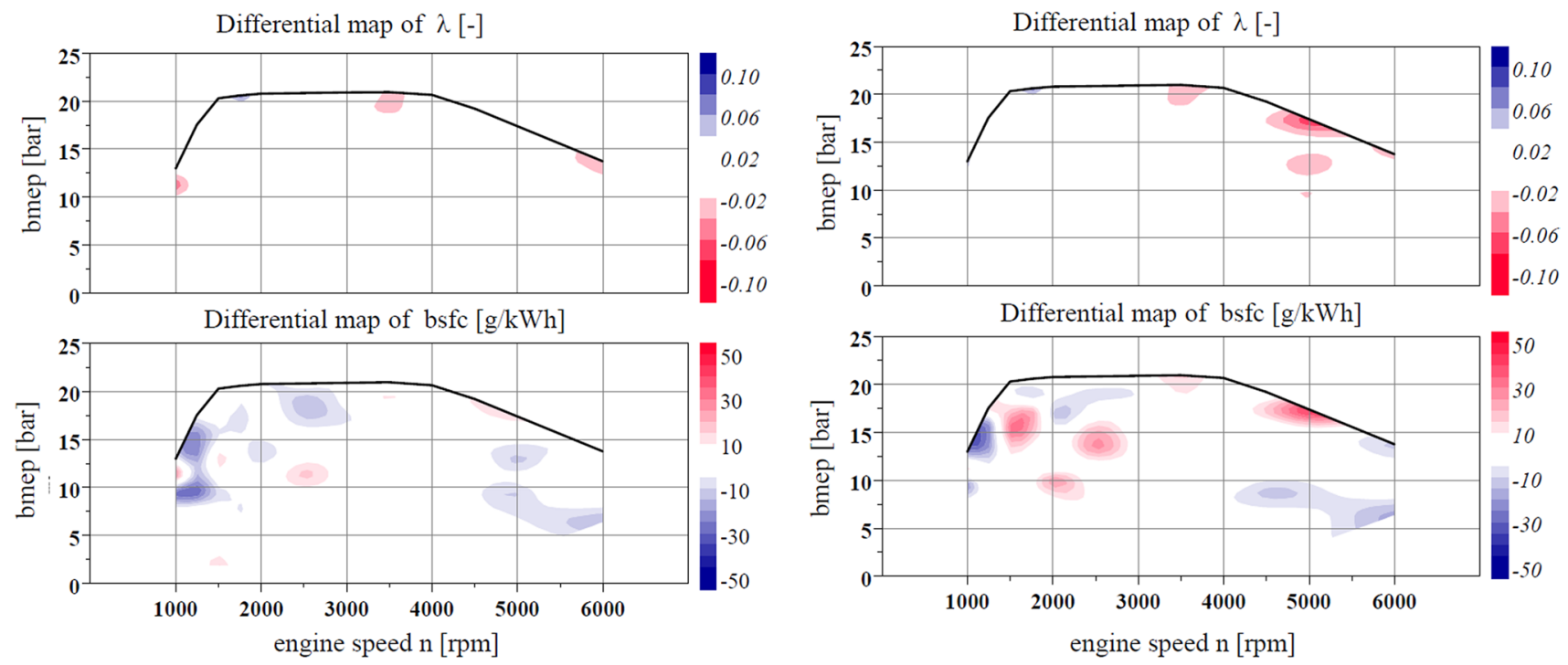

Fig. 11 Difference map of part \#08 — CAS feature with reduced NOK volume (left); Difference map of part \#12—CCV feature with reduced NOK volume (right) 
later and combustion is delayed, resulting in disadvantages in efficiency.

The comparison of the differential maps shows primarily the same operating characteristics of the two cylinder heads. A differentiation of the characteristics with regard to combustion chamber reduction is therefore not derivable (Fig. 11).

\subsection{Comparison of knock limits}

The ignition limit was determined at speeds of $2000 \mathrm{rpm}$ and $4000 \mathrm{rpm}$ in different load ranges. A clear differentiation could be identified especially at load points in the full load range.

Fig. 12 shows the measurements for the knock limit of the test parts at an operating point of $2000 \mathrm{rpm}$ and a BMEP of 19 bar. Here, there is a slight deviation in the combustion chamber characteristics to be valuated - characteristic CAS shows expected behaviour. With increasing compression ratio, the knock limit shifts to late. The volumetric characteristic has a uniform shift of the knock limit to late, which indicates a feature-dependent deterioration of the mixture formation. If the speed is increased, the opposite behaviour occurs. Figure 13 shows the measurements for the knock limit of the test parts at an operating point of $4000 \mathrm{rpm}$ and a BMEP of 17 bar. Here the volumetric characteristic shows an expected behaviour. As the compression ratio increases, the knock limit shifts to late, whereas the feature with a pure combustion chamber roof shift (CAS) does not allow for a clear differentiation. Regardless of the combustion chamber volume, the knock limit is shifted in a late direction compared to the reference measurement.

The tests to determine the characteristic knock limit indicate an influence of the combustion chamber shape. The combustion chamber shape manipulations shown here involve very large deviations from the actual nominal volume. In series production, however, the resulting widely differing combustion chamber volumes and the resulting shifts in ignition limits in this form in series engines are not to be expected. Further measurements of components with the same combustion chamber manipulations with regard to their feature-specific characteristics were investigated as OK components. However, no clear feature-specific findings could be deduced from the results. Only those combustion chambers with a strong deviation from the target volume showed feature-specific properties, which is why only results from NOK components are shown here.

\section{Summary and conclusion}

Combustion chamber shape deviations can have different causes. The combustion chamber shape deviations examined here refer to tolerances and deviations resulting from the production of blanks. To identify deviations due to the original shape, potential characteristics that can occur in series production were derived from the process chain of the crude production of a cylinder head. For the systematic investigation of the component characteristics, these deviations were manufactured in isolation and examined on the engine test bench. Since it cannot be excluded that further deviations can be found in the test parts, an additional transient mixture formation simulation was carried out, so that an isolated consideration of the form deviation characteristics can be considered.

To determine the influence of the combustion chamber shape and requirements of the potential test procedure, the effect of the named deviation characteristics had to be examined in a first step. For this purpose, limit sample components, i.e., components with strongly deviating combustion chamber volume characteristics, were simulated and metrologically examined and compared.

The simulations show little dependence of the combustion chamber characteristics. As these only occur in the case
Fig. 12 Knock limits of the and 19 bar NOK components at $2000 \mathrm{rpm}$
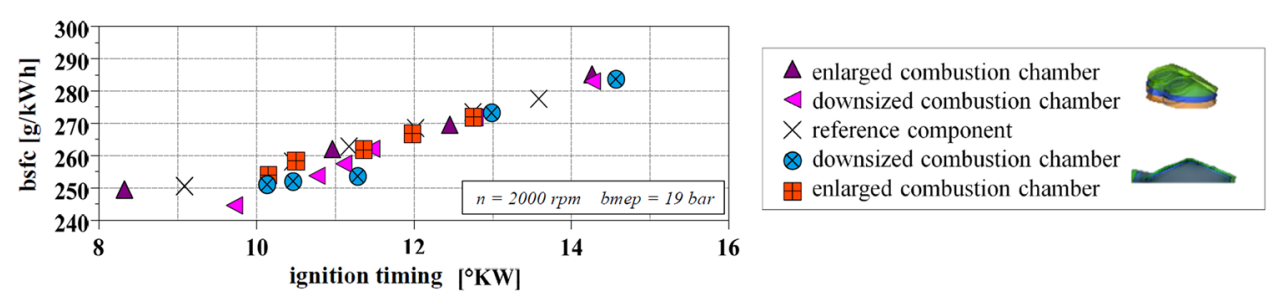

Fig. 13 Knock limits of the NOK components at $4000 \mathrm{rpm}$ and 17 bar

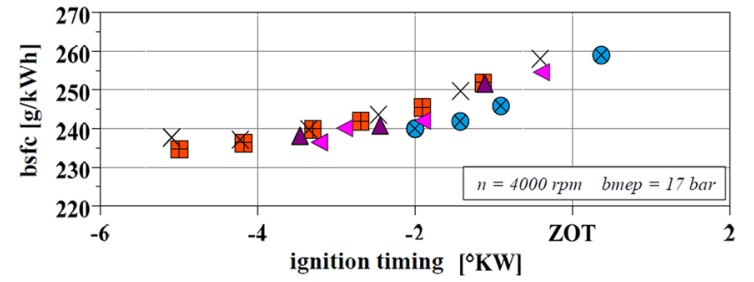

$\Delta$ enlarged combustion chamber

$\checkmark$ downsized combustion chamber $X$ reference component

$\otimes$ downsized combustion chamber

田 enlarged combustion chamber 
of very large deviations from the nominal dimension, only a minor influence on the mixture formation and thus on the operating behaviour can be derived here. The primary cause for the change in operating behaviour is the change in compression.

The measurements on the engine test bench show an identical behaviour. The steady-state map comparison shows the highest deviations from the comparison measurement in areas of high knock probability. The comparison of the characteristics with each other does not show any significant effects on the engine operation, so that the primary dependency here can also be attributed to the compression ratio.

The test parts shown here were manufactured with double the combustion chamber position tolerance compared to the series requirement. Limit samples with such large deviations are therefore not to be expected in series production. In the largest part of the operating field, the combustion chamber deviations were well-absorbed by the engine control system. However, full load could not be reached at the limits, especially near the low-end-torque (LET). In the case of greatly enlarged combustion chambers, this is due to the lack of compression, and in the case of greatly reduced combustion chambers, it is due to the ignition being adjusted to late timing and the boost pressure being lowered to prevent knocking. Although the differential maps show a slight improvement in fuel consumption, this is due to the fact that the reference measurement shows a load up to $20 \mathrm{Nm}$ higher. Such an influence is not to be expected for cylinder heads with combustion chamber deviations whose dimensions lie within the required tolerance band. Further investigations are planned to determine the sensitivity of the combustion chamber volume with lower or different combustion chamber volumes.

From the results available to date, no need for the development of complex features for imaging test procedures in series production can be derived due to the low engine-technical effects of combustion chamber deviations. The main finding of this documented investigation is that tolerancedeviations mostly act with their influence on the compression ratio. Thus, a check of the combustion chamber shape based on the compression ratio, i.e., the combustion chamber volume, is sufficient.

Acknowledgements The research project presented in this publication and its results have come about through the active commitment and great dedication of Dipl.-Ing. Torsten Stolt. Without him, the work on this topic would not have been possible. Unfortunately, Mr. Stolt passed away unexpectedly in the fall of 2020. This saddens everyone who has been involved in this project and worked closely with him over the past 4 years. In this sense, this publication is dedicated to Dipl.-Ing. Torsten Stolt in the name of all project participants.

Funding Open Access funding enabled and organized by Projekt DEAL.

Open Access This article is licensed under a Creative Commons Attribution 4.0 International License, which permits use, sharing, adaptation, distribution and reproduction in any medium or format, as long as you give appropriate credit to the original author(s) and the source, provide a link to the Creative Commons licence, and indicate if changes were made. The images or other third party material in this article are included in the article's Creative Commons licence, unless indicated otherwise in a credit line to the material. If material is not included in the article's Creative Commons licence and your intended use is not permitted by statutory regulation or exceeds the permitted use, you will need to obtain permission directly from the copyright holder. To view a copy of this licence, visit http://creativecommons.org/licenses/by/4.0/.

\section{References}

1. Nemak, GmbH., Audi, A.G .: Productsheet.

2. Eichlseder, H., Klüting, M., Piock, W.F.: Grundlagen und technologien des ottomotors, 1. Springer-Verlag/Wien (2008)

3. Beyerer, J., Puente León, F., Frese, C.: Automatische sichtprüfung methoden und praxis der bildgewinnung und bildauswertung. Springer (2012)

4. Dössel, O.: Bildgebende Verfahren in der Medizin. Von der Technik zur medizinischen Anwendung, 2., aktualisierte Aufl. 2016.

5. Keferstein, C.P., Marxer, M., Bach, C.: Fertigungsmesstechnik. Alles zu Messunsicherheit, konventioneller Messtechnik und Multisensorik. Springer (2018)

6. Stolt, T.; Blasek, S.: Realisierung von serienorientierten Messaufgaben im schnellen CT. Messung in Serie. microvista.de/realisierung-von-serienorientierten-Messaufgaben-im-schnellen-ct/.

7. Ambos, E., Brunke, O., Neuber, D., Lux, H., Stuke, I., Besser, W., Ziesman, M., Heikel, C., Huxol, A.: Schnelle computertomographen in der druckgussfertigung ein beachtenswerter schritt in der technologie. Giesserei 99, 40-49 (2012)

8. Microvista $\mathrm{GmbH}$ (Hrsg.): Inline-computertomographie als Qualitätstool in der Serienfertigung 2010.

9. Wurms, R.; Budack, R.; Grigo, M.; Mendl, G.; Heiduk, T.; Knirsch, S.: Der neue 2.01 Motor mit innovativem Rightsizing-ein weiterer Meilenstein der TFSI-Technologie. In: 36. Internationales Wiener Motorensymposium 60-67 (2015).

Publisher's Note Springer Nature remains neutral with regard to jurisdictional claims in published maps and institutional affiliations. 